\title{
Mixed-Valence Two-Legged MX-Ladder Complex with a Pair of Out-of-Phase \\ Charge-Density Waves
}

Atsushi Kobayashi and Hiroshi Kitagawa

Department of Chemistry, Faculty of Science, Kyushu University, Hakozaki 6-10-1, Higashi-ku, Fukuoka 812-8581, Japan.

\section{Supporting Information}

\section{Synthesis of $\left\{\left[(\text { dien }) \mathrm{Pt}^{\mathrm{IV}} \mathrm{Br}_{2}-b p y-\mathrm{Pt}^{\mathrm{II}}(\text { dien })\right] \mathrm{Br}_{4} \cdot 2 \mathrm{H}_{2} \mathrm{O}\right\}_{\infty}$.}

The starting material $\left[(\right.$ dien $) \mathrm{Pt}^{\mathrm{II}}-b p y-\mathrm{Pt}^{\mathrm{II}}($ dien $\left.)\right]\left(\mathrm{NO}_{3}\right)_{4}$ was obtained by the reaction of $\mathrm{Pt}^{\mathrm{II}}($ dien $)\left(\mathrm{NO}_{3}\right)_{2}$ and bpy in aqueous solution. To a methanol solution $(100 \mathrm{ml})$ of $\left[(\right.$ dien $) \mathrm{Pt}^{\mathrm{II}}-$ bpy- $-\mathrm{Pt}^{\mathrm{II}}($ dien $\left.)\right]\left(\mathrm{NO}_{3}\right)_{4}(150 \mathrm{mg}, 0.15 \mathrm{mmol})$ was added an excess amount of bromine $(2$ $\mathrm{ml}$ ) and then refluxed for 1 day. Filtration of this solution afforded the yellow powder of [(dien) $\mathrm{Pt}^{\mathrm{IV}} \mathrm{Br}_{2}-b p y-\mathrm{Pt}^{\mathrm{IV}} \mathrm{Br}_{2}$ (dien) $] \mathrm{Br}_{4}$ (yield: $150 \mathrm{mg}, 72 \%$ ). To an aqueous solution (4 ml) of equimolar of $\quad\left[(\right.$ dien $) \mathrm{Pt}^{\mathrm{II}}-b p y-\mathrm{Pt}^{\mathrm{II}}($ dien $\left.)\right]\left(\mathrm{NO}_{3}\right)_{4} \quad(20 \quad \mathrm{mg}, \quad 0.014 \quad \mathrm{mmol}) \quad$ and [(dien) $\mathrm{Pt}^{\mathrm{IV}} \mathrm{Br}_{2}-b p y-\mathrm{Pt}^{\mathrm{IV}} \mathrm{Br}_{2}$ (dien) $] \mathrm{Br}_{4}(20 \mathrm{mg} 0.014 \mathrm{mmol})$, an excess amount of $\mathrm{KBr}(200 \mathrm{mg}, 1.68$ mmol) was added. The dark green precipitate is instantly formed. The suspension was kept stirred for another hour at RT. The crude product was collected by filtration and recrystallized from water to afford $\left\{\left[(\text { dien }) \mathrm{Pt}^{\mathrm{IV}} \mathrm{Br}_{2}-b p y-\mathrm{Pt}^{\mathrm{II}}(\text { dien })\right] \mathrm{Br}_{4} \cdot 2 \mathrm{H}_{2} \mathrm{O}\right\}_{\infty}$ as green lustrous plate crystal (yield: $28 \mathrm{mg}$, $80 \%$ ) Elemental analysis (\%) calcd. for $\mathrm{C}_{18} \mathrm{H}_{34} \mathrm{Br}_{6} \mathrm{~N}_{8} \mathrm{Pt}_{2} \cdot 2 \mathrm{H}_{2} \mathrm{O}$ : C 17.05, H 3.02, N 8.84; found: C 17.24, H 2.94, N 8.94. 


\section{Raman spectrum of $\left\{\left[(\text { dien }) \mathrm{Pt}^{\mathrm{IV}} \mathrm{Br}_{2}-b p y-\mathrm{Pt}^{\mathrm{II}}(\text { dien })\right] \mathrm{Br}_{4} \cdot 2 \mathrm{H}_{2} \mathrm{O}\right\}_{\infty}$.}

Raman spectra of single crystal were recorded on a JASCO NRS-1000 single monochromator with Kaiser Optical Systems Holographic super-notch filter using a microscope. A Showa Optronics GLG5601 He-Ne laser provided the exciting line $(632.8 \mathrm{~nm})$.

Figure S1 shows the Raman spectrum of $\left\{\left[(\text { dien }) \mathrm{Pt}^{\mathrm{IV}} \mathrm{Br}_{2} \text {-bpy- } \mathrm{Pt}^{\mathrm{II}}(\text { dien })\right] \mathrm{Br}_{4} \cdot 2 \mathrm{H}_{2} \mathrm{O}\right\}_{\infty}$ at room temperature. The peak assigned as $v(\mathrm{Pt}-\mathrm{Br})$ mode was strongly observed at $172 \mathrm{~cm}^{-1}$ with several of its overtones. This strongly activated overtone progression (of up to eight members) is derived from resonance with the charge-transfer $(\mathrm{CT})$ transition from $\mathrm{Pt}^{\mathrm{II}}$ to adjacent $\mathrm{Pt}^{\mathrm{IV}}$ sites within one leg, which is observed at $2.1 \mathrm{eV}$ in the diffuse reflectance spectrum, as shown in inset of Figure $\mathrm{S} 2$. 
Diffuse reflectance spectrum of $\left\{\left[(\text { dien }) \mathrm{Pt}^{\mathrm{IV}} \mathrm{Br}_{2}-b p y-\mathrm{Pt}^{\mathrm{II}}(\text { dien })\right] \mathrm{Br}_{4} \cdot 2 \mathrm{H}_{2} \mathrm{O}\right\}_{\infty}$.

Diffuse reflectance spectra of the complex diluted in $\mathrm{CaF}_{2}$ powder were recorded on a JASCO V-570 spectrophotometer equipped with a JASCO ISN-470 60 $m m \phi$ integrating-sphere apparatus. Obtained reflectance spectra were converted to absorption spectra using the Kubelka-Munk function $F\left(R_{\infty}\right)$.

Figure S2 shows the diffuse reflectance spectrum of $\left\{\left[(\text { dien }) \mathrm{Pt}^{\mathrm{IV}} \mathrm{Br}_{2}-b p y-\mathrm{Pt}^{\mathrm{II}}(\text { dien })\right] \mathrm{Br}_{4} \cdot 2 \mathrm{H}_{2} \mathrm{O}\right\}_{\infty} \quad$ at $\quad$ room temperature. The peak appeared at $2.1 \mathrm{eV}$ is attributable to the charge-transfer transition from $\mathrm{Pt}^{\mathrm{II}}$ to adjacent $\mathrm{Pt}^{\mathrm{IV}}$ sites within each PtBr leg.

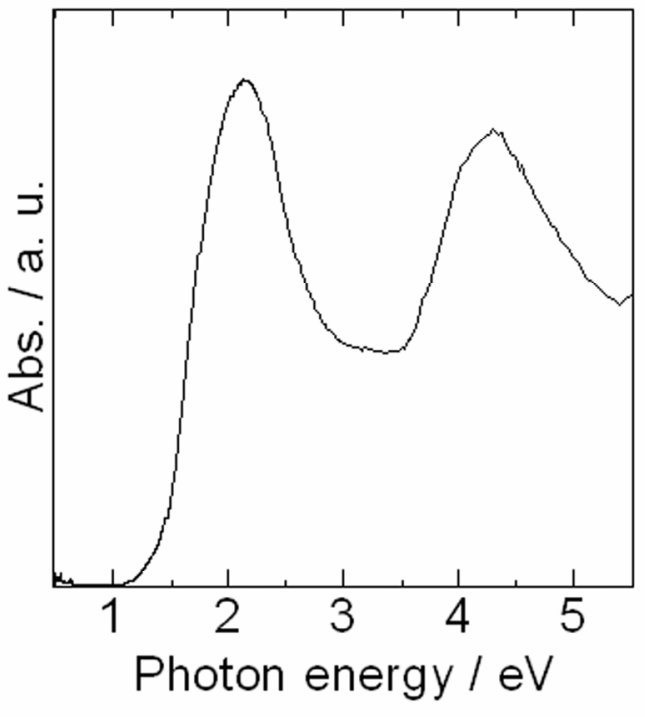

Figure S2. Diffuse reflectance spectrum of $\left\{\left[(\text { dien }) \mathrm{Pt}^{\mathrm{IV}} \mathrm{Br}_{2}-\text { bpy }-\mathrm{Pt}^{\mathrm{II}}(\text { dien })\right] \mathrm{Br}_{4} \cdot 2 \mathrm{H}_{2} \mathrm{O}\right\}_{\infty}$ 


\section{Intervalence charge-transfer excitation energies on MX-chain and MX-ladder.}

As shown in Figure S3, the charge-transfer excitation energy $\left(E_{\mathrm{CT}}\right)$ in the MX-chain system can be given by $E_{\mathrm{CT}}=8 S+$ $3 V_{\text {chain }}-U$, where $S$ is the electron-lattice interaction, $V_{\text {chain }}$ is the nearest neighbor inter-site Coulomb repulsion along the 1D

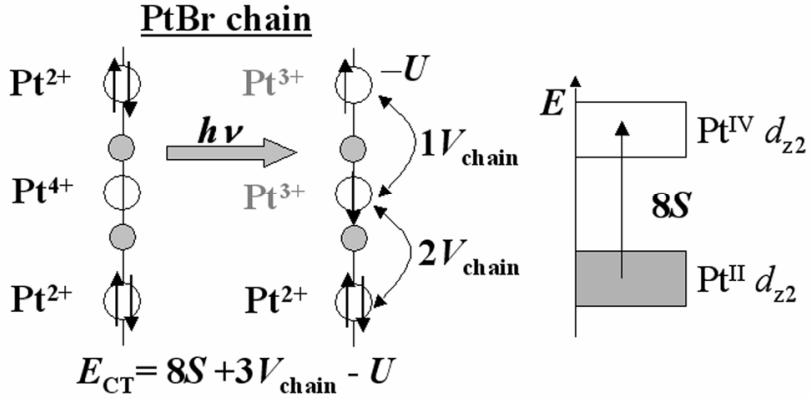

Figure S3. Schematic diagram of the chargetransfer excitation in the $\mathrm{PtBr}$ chain. chain and $U$ is the on-site Coulomb repulsion, because the required energy to transition from $\mathrm{Pt}^{\mathrm{II}}$ to $\mathrm{Pt}^{\mathrm{IV}}$ sites is estimated as follows.

1) The transition energy corresponds to the energy difference between the $d_{\mathrm{z} 2}\left(\mathrm{Pt}^{\mathrm{II}}\right)$ and $d_{\mathrm{z} 2}\left(\mathrm{Pt}^{\mathrm{IV}}\right)$ bands derived from the electron-lattice interaction, which is equal to $8 S$.

2) In the excited state, the inter-site Coulomb repulsion $V_{\text {chain }}$ occurs between adjacent $\mathrm{Pt}^{3+}$ and $\mathrm{Pt}^{2+}$ sites, corresponding to the $3 V_{\text {chain }}$.

3) The on-site Coulomb repulsive energy $U$ in the ground state disappeared in the excited state, which corresponds to $-U$.

On the other hand, the $E_{\mathrm{CT}}$ in the two-legged MX-ladder system can be given by $E_{\mathrm{CT}}=8 S+2 V_{\text {rung }}+3 V_{\text {chain }}-U$, where $V_{\text {rung }}$ is the inter-site Coulomb repulsion along the rung as shown in Figure S4. The nearest neighbor inter-site Coulomb repulsive energy along the

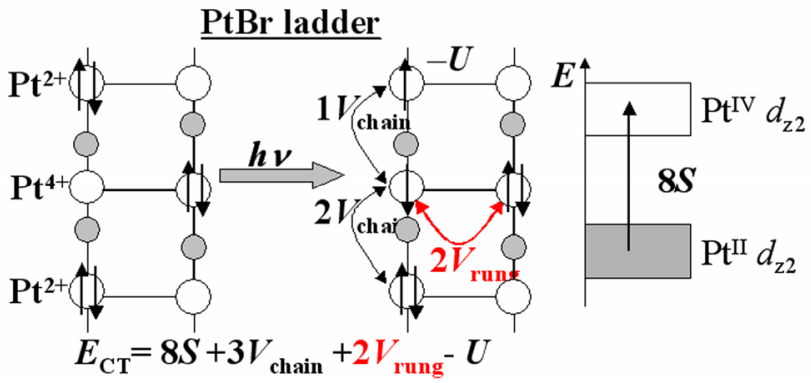

Figure S4. Schematic diagram of the chargetransfer excitation in the $\mathrm{PtBr}$ ladder. rung $2 V_{\text {rung }}$ is required in the two-legged MX-ladder system. 